\title{
ERA UMA VEZ O PISA
}

Alexandre Ventura ${ }^{1}$

Era uma vez um programa no setor educacional que conseguiu ter uma visibilidade e uma influência nas políticas educacionais de inúmeros países como nenhum outro. Chamava-se PISA - Programme for International Student Assessment e era publicado por uma instituição renomada e muito poderosa designada OCDE - Organização para a Cooperação e Desenvolvimento Econômico. A história poderia começar desta maneira.

Em virtude da projeção à escala planetária do PISA, o tema da educação passou a ser abordado pela mídia de uma maneira intensa na época da publicação dos sucessivos relatórios. Desde a divulgação dos seus primeiros resultados em 2000, o PISA foi consistentemente objeto de debates intensos envolvendo predominantemente académicos e pesquisadores do setor educacional, políticos, economistas, fazedores de opinião e jornalistas. Depois de 20 anos de PISA, podemos dizer que ele se tornou incontornável nas agendas educacional, política e mediática. O PISA, a par de outros programas internacionais como o TIMSS - Trends in International Mathematics and Science Study, o PIRLS - Progress in International Reading Literacy Study, o ePIRLS - International Results in Online Informational Reading, o PIAAC - Program for the International Assessment of Adult Competencies (também conhecido como Survey of Adult Skills), o TALIS - Teaching and Learning International Survey, faz parte de uma tendência no sentido do que poderemos designar de infraestruturas globais de prestação de contas que vão beber inspiração à sociedade de auditoria, ou audit society (BOWERMAN et al., 2000; Power, 1999).

Esta tendência, de contornos diáfanos insere-se numa corrente de conceções, discursos e abordagens fabricados transnacionalmente, 'transnationally fabricated' (CARVALHO, 2012, p. 73) que funcionam como embaixadores de uma governança globalizada no âmbito da educação que crescentemente influenciam o que acontece nas escolas em todo o Mundo (LEWIS, 2020).

\footnotetext{
1 Universidade de Aveiro, Portugal. E-mail: alexandre.ventura@ua.pt
} 
Por via do PISA, a OCDE desenvolve, legitima e instrumentaliza um programa técnico que promove uma regulação transnacional das políticas educacionais impositiva de "diagnósticos, metodologias, práticas, soluções" (BARROSO, 2018, p. 1084) de escopo limitado e sempre sob os auspícios da teoria do capital humano e o viés da economia.

O PISA é a "estrela" mais notória na panóplia de exemplos de programas promovidos pela OCDE e outras organizações que operam à escala planetária no sentido de influenciar as políticas públicas dos países de acordo com uma visão por muitos considerada unidimensional. À medida que cresce a notoriedade do programa, aumenta a eficiência da organização que o promove no sentido de influenciar e mesmo configurar os processos de tomada de decisões e as políticas públicas dos países. Estamos, portanto, numa área de intervenção em que uma organização com influência global faz por via de um programa a avaliação das políticas públicas no setor educacional dos países participantes. Assim, desencadeia-se um processo de prestação de contas, mais ou menos forçado, e dá-se resposta às expetativas de participação na decisão pública manifestadas por muitos setores da sociedade civil. Em ambos os casos, isso conseguese sobretudo através da difusão em grande escala dos resultados do PISA e pela implicação de muitos cidadãos nos debates decorrentes ao serviço de uma multiplicidade de agendas, posicionamentos e estratégias de modesta clareza. A divulgação dos resultados coloca políticas e políticos sob as luzes dos holofotes mediáticos e cria oportunidades para fazedores de opiniões procurarem interpretar esses resultados e legitimarem ou criticarem as opções adotadas.

A par deste movimento, ocorre aquele que é provavelmente 0 maior crescimento exponencial de educação comparada na história da humanidade em que países e regiões do Mundo se digladiam para migrar em sentido ascendente no ranking do PISA e ninguém quer ficar mal na foto. A globalização que cria as condições para que este cenário aconteça e que ao mesmo tempo beneficia desta tendência é imposta a partir de cima e é enquadrada por uma ideologia neoliberal (TORRES, 2018, p. 109). Nunca outro programa no setor educacional conseguiu agitar tanto os debates globalizados sobre qualidade em educação, políticas educacionais que garantam melhoria, receitas milagrosas que impactem positivamente o sucesso dos alunos, erros crassos que justifiquem quedas de posição no ranking e por aí fora. Os debates acalorados são normalmente feitos através do confronto de posições maniqueístas e por via de simplificações grosseiras de realidades extremamente complexas. A frustração decorrente da incapacidade para explicar sucessos ou fracassos leva à fabricação de cenários verosímeis, mas que manifestam uma relação modesta com a realidade. Quando os resultados são bons, os decisores políticos tendem a engalanar seus discursos com as grinaldas da sua autoria das medidas de política 
educacional que deram origem à melhoria. Se os resultados indicam estagnação ou retrocesso, convenientemente são identificados bodes expiatórios tais como governos anteriores, as escolas ou os professores.

Em educação, os programas têm normalmente vida curta. O PISA destaca-se pela sua longevidade e pelo seu crescente impacto. O primeiro PISA, em 2000, incluiu 32 países. Entretanto, em 2018, participaram neste programa quase 80 nações e há previsões para que esse número dobre em 2030. Se se concretizar tal vaticínio, mais de $80 \%$ das nações mundiais terão alunos participando no PISA. Será uma espécie de Jogos Olímpicos da Educação. Em grande medida, esse sucesso exponencial do programa deve-se ao fato de ser promovido por uma organização com enorme influência no areópago das nações e por ter na sua base um roteiro comunicacional apelativo de enorme eficácia junto do comum dos cidadãos. Na realidade, a justificativa do PISA é que um desempenho superior dos alunos nas suas provas estandardizadas é evidência de políticas educacionais igualmente superiores. Dentro dessa lógica, os países com desempenho inferior deverão mimetizar as políticas educacionais desenvolvidas pelos países mais bem colocados no ranking (FENIGER; LEFSTEIN, 2014, p. 845). Esta simplicidade é extremamente atraente para o cidadão comum que deseja sempre soluções milagrosas, claras e rápidas para os problemas. Cria-se assim ordem no caos, simplifica-se o complexo e alimenta-se o logro de que é fácil melhorar rapidamente sistemas educacionais. Esta narrativa tem os ingredientes das estórias para crianças. Mas não seremos nós crianças toda a vida? Na verdade, os brinquedos é que vão mudando.

As soluções simples exercem uma atração forte para o público em geral. Mas não há soluções simples para realidades heterogéneas e extremamente complexas como são os sistemas educacionais, os sistemas económicos e os sistemas sociais. Por outro lado, uma organização tão poderosa e pervasiva quanto a OCDE promove agendas explícitas e ocultas que privilegiam certas políticas e interesses em detrimento de outros. O poder das políticas promovidas pela OCDE por intermédio dos governos que direta ou indiretamente são por elas influenciados é muito significativo. Efetivamente, a "marca" OCDE, à semelhança do que acontece com os processos de notoriedade de alguns produtos no âmbito do marketing, converteu-se ao longo dos anos no padrão do desejável e das boas práticas a replicar. Para muitos, o PISA constitui uma espécie de "selo de aprovação", acabando também por funcionar como um disruptor no panorama educacional e das políticas públicas. Isso acontece porque este programa alavanca mudanças na 
configuração das medidas e prioridades adotadas por governos relativamente a seus sistemas educacionais (PIRO, 2019).

Independentemente da benignidade que essa influência frequentemente tem, o processo desencadeia uma visão de túnel e afeta a diversidade de situações e soluções através de uma homogeneização envolvendo promotores e destinatários das políticas de mudança e de reforma (CERNA, 2013). Essa caraterística é bem clara na agenda e na abordagem assumida pela OCDE quando refere na sua valência de definição de standards que "encoraja países a fazer melhor através do desenvolvimento de padrões internacionalmente acordados para que todos os envolvidos ajam de acordo com as mesmas regras e cooperem para atingirem objetivos comuns" (OCDE, 2020). Inevitavelmente, ocorre por esta via um estreitamento da panóplia de opções e verifica-se uma imposição disfarçada de modelos e soluções sem ter em conta a necessidade de tomar em consideração a dimensão local como espaço relevante de debate (Lewis, 2020) e sensibilidades históricas e sociais. Nessa linha de pensamento, as culturas dos diferentes países e regiões e as especificidades e idiossincrasias dos ambientes escolares influenciam o sucesso educacional e devem ser cuidadosamente tomadas em consideração e reinterpretadas (Soh, 2018). Por outro lado, é muito interessante verificar como em diferentes países diversos stakeholders usam e abusam dos resultados do PISA em função das suas agendas de reforma, de pressão ou de legitimação (WALDOW; STEINER-KHAMSI, 2019).

Em suma, regressando ao tom metafórico-infantil usado no início deste modesto texto, o PISA nem representa o Chapeuzinho Vermelho, nem deve ser revestido com a pele do Lobo Mau. O PISA patenteia um conjunto de virtualidades significativas de entre as quais destacaremos a visibilidade acrescida sobre o setor educacional e a promoção do debate a seu respeito, a partilha de boas práticas e de exemplos galvanizadores, e a disponibilização de dados e informações sobre o desempenho de um crescente número de sistemas educativos. No entanto, o crescimento do protagonismo e da influência do PISA clamam por um concomitantemente incrementado espírito crítico na análise e interpretação dos seus resultados, bem como por uma maior cautela na adoção ou adaptação de medidas de política educacional decorrentes de interpretações lineares sobre os seus ranqueamentos.

\section{REFERÊNCIAS}


BARROSO, J. A transversalidade das regulações em educação: modelo de análise para o estudo das políticas educativas em Portugal. Educação e Sociedade, 39(145), 1075-1097, 2018. https://doi.org/10.1590/es0101-73302018214219.

BOWERMAN, M., Raby, H., \& HUMPHREY, C. In: Search of the Audit Society: Some Evidence from Health Care, Police and Schools. International Journal of Auditing, 4, 71-100, 2000.

Carvalho, L. M. The Fabrications and Travels of a Knowledge-Policy Instrument. European Educational Research Journal, 11, 2012. https://doi.org/10.2304/eerj.2012.11.2.172.

CERNA, L. The nature of policy change and implementation: a review of different theoretical approaches. 2013. 1-31.

FENIGER, Y.; LEFSTEIN, A. How not to reason with PISA data: an ironic investigation. Journal of Education Policy, 29(6), 845-855, 2014. https://doi.org/10.1080/02680939.2014.892156

LEWIS, Steven. PISA, Policy and the OECD: Respatialising Global Educational Governance Through PISA for Schools. Berlin: Springer Nature, 2020.

OCDE. Discover the OECD. Better policies for better lives. Paris: OECD, 2020.

http://www.oecd.org/about

PIRO, J. M. The Primacy of PISA: How the World's Most Important Test Is Changing Education Globally. Lanham, Maryland: Lexington Books, 2019.

POWER, M. The Audit Society. Rituals of Verification. Oxford University Press, 1999.

SOH, Kaycheng. PISA and PIRLS: The Effects of Culture and School Environment. Singapore: WSPC, 2018.

TORRES, C. A. The state of the art in comparative education and WCCES at a crossroads in the 21st century. Revista Lusofona de Educacao, 41(41), 107-124, 2018.

https://doi.org/10.24140/issn.1645-7250.rle41.07

WALDOW, Florian; STEINER-KHAMSI, Gita. Understanding PISA's Attractiveness: Critical Analyses in Comparative Policy Studies (New Directions in Comparative and International Education). Londres: Bloomsbury Academic, 2019. 